\title{
FACTORS AFFECTING Hg (II) ADSORPTION IN SOILS FROM THE RIO NEGRO BASIN (AMAZON)
}

\author{
Patricia Miretzky \\ Centro de Estudios Transdiciplinarios del Água, Facultad de Ciencias Veterinarias, Universidad de Buenos Aires, Chorroarín \\ 280, Buenos Aires (1427) - Argentina \\ Márcia Cristina Bisinoti e Wilson F. Jardim* \\ Instituto de Química, Universidade Estadual de Campinas, CP 6154, 13084-971 Campinas - SP, Brasil \\ Júlio César Rocha \\ Instituto de Química, Universidade Estadual Paulista, CP 355, 14801-970 Araraquara - SP, Brasil \\ Recebido em 12/4/04; aceito em 13/10/04; publicado na web em 2/2/05
}

\begin{abstract}
FACTORS AFFECTING Hg (II) ADSORTION IN SOILS FROM THE RIO NEGRO BASIN (AMAZON). Mercury (II) adsorption studies in top soils (top $10 \mathrm{~cm}$ ) from the Rio Negro basin show this process depends strongly on some selected parameters of the aqueous phase in contact with the soils. Maximum adsorption occurred in the pH range 3.0-5.0 (>90\%). Dissolved organic matter shows an inhibitory effect on the availability of $\mathrm{Hg}$ (II) to be adsorbed by the soils, whereas a higher chloride content of the solution resulted in a lower adsorption of $\mathrm{Hg}$ (II) at $\mathrm{pH}$ 5.0. Soils with higher organic matter content were less affected by changes in the salinity. An increase in the initial $\mathrm{Hg}$ (II) concentration increased the amount of $\mathrm{Hg}$ (II) adsorbed by the soil and decreased the time needed to reach equilibrium. A Freundlich isotherm provided a good model for $\mathrm{Hg}$ (II) adsorption in the two types of soil studied. The kinetics of $\mathrm{Hg}$ (II) adsorption on Amazonian soils showed to be very fast and followed pseudo-second order kinetics. An environmental implication of these results is discussed under the real scenario present in the Negro River basin, where acidic waters are in contact with a soil naturally rich in mercury.
\end{abstract}

Keywords: mercury; soils; Freundlich isotherm.

\section{INTRODUCTION}

Mercury is an extremely toxic pollutant that is currently emitted mainly by low level industrial sources. It is distributed globally through the atmosphere, from where it precipitates on the surface of the Earth, reaches the aquatic organisms, accumulates in fish and finally affects the health of human populations. Mercury is the most toxic of all elements ${ }^{1}$ and, so far, it has shown no beneficial biological function ${ }^{2,3}$.

Mercury contamination from gold mining was considered to be one of the worst environmental problems affecting the Amazon ecosystem ${ }^{4-7}$. Nevertheless, in recent years, there have been numerous indications that, in the Negro River Basin (Amazon), naturally occurring mercury leaching from soil is the major pathway to mercury enrichment in the region ${ }^{8}$. Extensive weathering and leaching cycles during a major part of the year due to flooding lead to the decrease of mercury ions in soils, constantly replaced by atmospheric deposition, and in an increase of the mercury concentration in Negro River waters. Deforestation and agricultural practices increase leaching and erosion of soils. The acceleration of these processes, combined with the natural release of mercury into aquatic ecosystems, are important factors leading to high mercury content in predatory fish in this area ${ }^{9}$.

Given the high levels of mercury in the soils of the northern Amazon and the health risks associated with the element, an insight into the adsorption of mercury in this matrix is extremely important. Data on the sorption of inorganic Hg (II) in soils are available in the literature ${ }^{10-18}$ but few deal with Amazonian soils, which are very rich in organic matter ${ }^{19,20}$. It is important to note that experimental

*e-mail: wfjardim@iqm.unicamp.br work is usually done at very high mercury concentrations that may occur at contaminated sites, but are unlikely in natural environments.

The purpose of the present paper is to evaluate the effect of $\mathrm{pH}$, ionic strength and dissolved organic matter on mercury (II) adsorption in two different Amazon top soils, in batch experiments using relatively low concentrations $\left(\mu \mathrm{g} \mathrm{L}^{-1}\right)$ of mercury solutions. The adsorption of mercury on soils cannot be explained only by equilibrium reactions as transport phenomena and chemical reactions are often experimentally inseparable. Kinetic studies were also performed to predict mercury transport and fate in soils and to support possible environmental management decisions.

\section{EXPERIMENTAL PART}

\section{Materials and methods}

Soils

Two different types of soils, sampled near Iara Lake ( $1^{\circ} 20.010^{\prime}$ S, 62 ${ }^{\circ} 03.809^{\prime} \mathrm{W}$, humic gley soil), and Carvoeiro 2 ( $1^{\circ} 23.615^{\prime} \mathrm{S}$, $61^{\circ} 58^{\prime} \mathrm{W}$, hydromorphic alluvial), were collected from the so called "igapó", or seasonally flooded forest, during the dry season, both in a black water river basin, with different organic matter contents. The two types of soils were collected from the A horizon $(0-10 \mathrm{~cm})$ and their principal characteristics are listed in Table 1. After air drying up to 15 days, soil samples were thoroughly mixed and passed through a $2 \mathrm{~mm}$ sieve before use.

Granulometric determination in soils was made by the pipette method, based on the Stockes Law, where small particles settle with constant speed in water or other fluids ${ }^{21}$. Density was measured using the ring procedure, where non-deformed soil samples are withdraw with a stainless steel ring of known volume and weighed upon received in the laboratory. 
Table 1. Negro river basin, soil characteristics

\begin{tabular}{lcccccccc}
\hline Soil & $\mathrm{pH}$ & Organic matter/\% & $\mathrm{C} / \mathrm{N}$ & Sand $/ \%$ & Silt/\% & Clay/\% & $\mathrm{Hg}_{(\mathrm{II}) / \mu \mathrm{g} \mathrm{kg}}{ }^{-1}$ & $\mathrm{Density}_{\mathrm{g} \mathrm{cm}}{ }^{-3}$ \\
\hline Iara & 3.4 & 24.7 & 16.0 & 39.8 & 40.1 & 20.1 & 281 & 1.1 \\
Carvoeiro 2 & 3.6 & 10.1 & 17.8 & 40.2 & 41.8 & 18.0 & 107 & 1.6 \\
\hline
\end{tabular}

\section{Reagents}

All chemicals used were of analytical-reagent grade. Milli-Q quality water (Millipore, USA) was used throughout. $\mathrm{NaCl}$ (Mallinckrodt ) was dissolved in water to obtain a $1000 \mathrm{mg} \mathrm{L}^{-1}$ stock solution. A 5\% stock solution of Humic acid (HA Aldrich) was prepared by dissolving the HA in water. Mercury chloride (Merck) was used from a $1000 \mathrm{mg} \mathrm{L}^{-1}$ stock solution. Nitric acid $\left(\mathrm{HNO}_{3}\right)$ solution $\left(0.01 \mathrm{~mol} \mathrm{~L}^{-1}\right)$ was prepared by dilution of concentrated acid (Mallinckrodt) and $\mathrm{NaOH}$ (Merck) was dissolved in water to obtain a $0.01 \mathrm{~mol} \mathrm{~L}^{-1}$ solution. The $10 \%$ (w/v) $\mathrm{SnCl}_{2}$ (Nuclear) solution was made by dissolving the salt in $10 \%(\mathrm{v} / \mathrm{v})$ $\mathrm{HCl}$ (Mallinckrodt) solution. Appropriate dilutions of stock solutions were made using Milli-Q water.

All the glassware used for dilution, storage and experiments was cleaned with Extran detergent, thoroughly rinsed with tap water, soaked overnight in a $20 \% \mathrm{HNO}_{3}$ solution and finally rinsed with Milli-Q water before use.

\section{Experimental design}

The influence of the $\mathrm{pH}$, the $\mathrm{NaCl}$ and $\mathrm{HA}$ concentrations on mercury (II) adsorption in soils was investigated in batch experiments, where $30.0 \pm 0.2 \mathrm{mg}$ of soil were suspended in $25.0 \mathrm{~mL}$ of $\mathrm{Hg}$ (II) solutions. All experiments were carried out using Pyrex erlenmayers and performed in duplicate, whereas total mercury determination was made in triplicate (relative error $<1.0 \%$ for the vast majority of obtained results). The organic content of the aqueous phase was adjusted using the HA solution added to obtain a range of $10-100 \mathrm{mg} \mathrm{L}^{-1}$ DOC. The experiment on the effect of $\mathrm{NaCl}$ and $\mathrm{HA}$ on $\mathrm{Hg}$ (II) adsorption was carried out at fixed $\mathrm{pH}$ of 5.0.

Kinetic studies were performed using different $\mathrm{Hg}$ (II) concentrations $\left(24 ; 39 ; 83 ; 117\right.$ and $193 \mu \mathrm{g} \mathrm{L}^{-1}$ for Iara soil and 8; 11; 26; 48 ; 97 and $109 \mu \mathrm{g} \mathrm{L}^{-1}$ for Carvoeiro 2 soil) in soil suspensions for $90 \mathrm{~min}$ in a rotary shaker at $140 \mathrm{rpm}$ and at room temperature. Preliminary experiments of adsorption kinetics indicated that a period of 90 min was sufficient to attain equilibrium for all of the $\mathrm{Hg}$ (II) solutions. At the end of the shaking period, samples were filtered using $0.45 \mu \mathrm{m}$ acetate cellulose membrane (Micro Separations Inc., MSI) and after filtration the $\mathrm{pH}$ was fixed at 5.0 for all experiments. The initial and final total mercury concentrations were determined in the aqueous phase. All the obtained values of total $\mathrm{Hg}$ concentration in adsorption experiments were corrected from blanks performed under the same conditions but in the absence of adsorbent species when using either $\mathrm{NaCl}, \mathrm{NaOH}, \mathrm{HCl}$ or $\mathrm{HA}$. The initial mercury concentration was determined just before starting the shaking step. Adsorption was calculated from the difference between the initial concentration of $\mathrm{Hg}$ in solution and the equilibrium concentration.

\section{Instruments}

Total mercury was determined after the oxidation step using a $0.02 \mathrm{~mol} \mathrm{~L}^{-1} \mathrm{BrCl}$ solution, where the excess of $\mathrm{BrCl}$ was eliminated by adding $30 \%(\mathrm{w} / \mathrm{v})$ hydroxylamine chloride. The aqueous phase was analysed using Cold Vapour Atomic Absorption Spectrometry (CVAAS) (Buck Scientific 400-A) coupled to a Flow Injection Analysis System (FIA) ${ }^{22}$. Though total mercury concentration was measured, previous experimental data (not presented here), showed that $\mathrm{Hg}$ (II) (or reactive mercury) concentration and total mercury concentration were identical. In this study, we will refer to $\mathrm{Hg}$ (II) in all experiments.

Dissolved organic matter (DOC) was determined using a Shimadzu, Model TOC-5000 total organic carbon analyser.

\section{RESULTS AND DISCUSSION}

\section{Influence of the $\mathrm{pH}$}

The amount of $\mathrm{Hg}$ (II) adsorbed (here expressed as Q, in $\mu \mathrm{g} \mathrm{Hg}$ $\mathrm{g}^{-1}$ soil) by the Iara and Carvoeiro 2 soil samples as a function of $\mathrm{pH}$ is shown in Figure 1. In the $\mathrm{pH}$ range 3.0-5.0, maximum adsorption occurred for both types of soils, yielding a ratio $(\mathrm{R})$ which is the ratio between the amount of metal adsorbed by the soil and the amount of $\mathrm{Hg}$ initially added, of $95.9 \%$, and $93.5 \%$ for Iara and Carvoeiro 2, respectively. At $\mathrm{pH} 9.0$, the $\mathrm{R}$ value decreases to 37.2 and $46.2 \%$ for these two samples. The interation between $\mathrm{Hg}$ (II) species in the aqueous phase with binding sites at the soil surface as a function of $\mathrm{pH}$ can be explained by looking at both the aquatic chemistry of mercury species and the soil characteristics. In terms of the solid surface, the decrease of $\mathrm{Hg}$ (II) adsorption onto soil particles at $\mathrm{pH} 9$ can be explained by two factors: a) a higher $\mathrm{pH}$ favours the leaching of organic matter from the solid phase thus resulting in a decrease of surface adsorption sites in the soil, and b) this organic matter, when present in the aqueous phase, can enhance the concentration of dissolved Hg (II) complexes, inhibiting adsorption. This fact was more evident for Iara soil (24.7\% soil organic matter) than for Carvoeiro 2 soil $(10.1 \%)$. The results obtained are in agreement with the ones published by Yin et al. ${ }^{12}$.
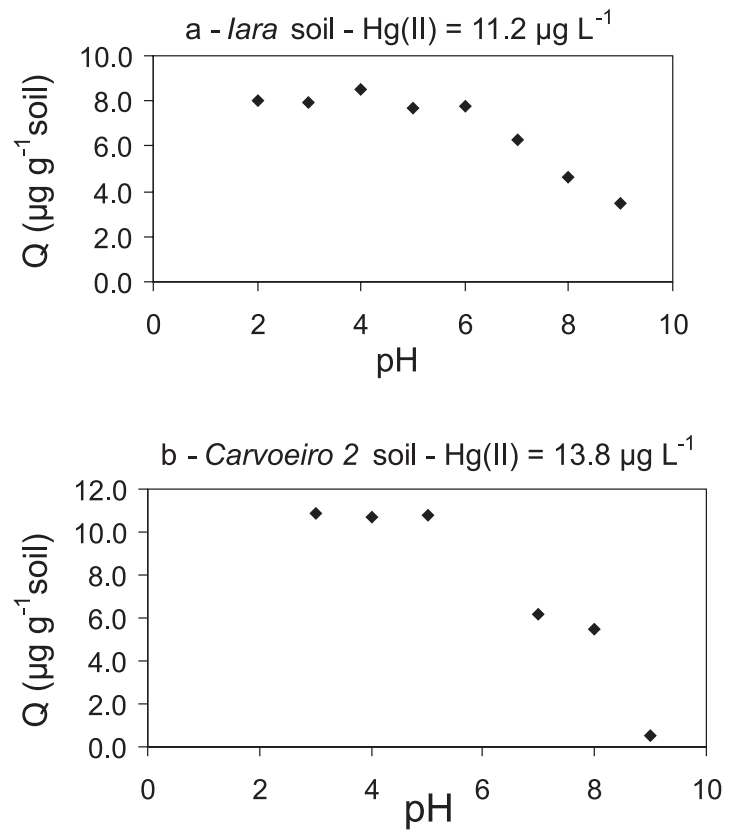

Figure 1. Influence of the $\mathrm{pH}$ on the amount of $\mathrm{Hg}$ (II) adsorbed by (a) Iara soil; (b) Carvoeiro 2 soil 
It has been observed that $\mathrm{Hg}$ (II) species can be reduced in the presence of naturally occurring organic material ${ }^{13}$. Rocha et al. ${ }^{13}$ found that the $\mathrm{Hg}$ (II) reduction by Negro River soil humic substances required almost $40 \mathrm{~h}$ to be completed. Schnoor ${ }^{14}$ pointed out that $\mathrm{Hg}$ (II) reduction is usually slow and may be not taken into account.

Speciation models used to investigate the predominant mercury species in the aqueous phase show that at very low $\mathrm{pH}(\mathrm{pH}<3)$, the dominant inorganic species are $\mathrm{Hg}^{2+}$ and $\mathrm{HgCl}^{+}$, with $\mathrm{HgCl}_{2}$ being the minor one. As an example, when $\mathrm{Hg}$ (II) $=50 \mathrm{nmol} \mathrm{L}^{-1}$ and $\mathrm{Cl}^{-}=0.1 \mu \mathrm{mol} \mathrm{L}{ }^{-1}$, at $\mathrm{pH} 2, \mathrm{Hg}^{2+}$ and $\mathrm{HgCl}^{+}$represent 65 and $30 \%$ respectively of total mercury present in the aqueous phase (Figure 2 ). $\mathrm{HgCl}_{2}$ is poorly adsorbed by inorganic species ${ }^{23}$. At low $\mathrm{pH}$, the soil surface has high positive net charge ${ }^{24}$ so adsorption is not favourable for $\mathrm{Hg}^{2+}$ and $\mathrm{HgCl}^{+}$cationic species. The high adsorption at $\mathrm{pH} 3-5$ is mainly due to the strong Lewis acidic nature of $\mathrm{Hg}$ (II) $\left(\mathrm{pK}_{\mathrm{OH}, 1}=3.87\right.$ and $\left.\mathrm{pK}_{\mathrm{OH}, 2}=2.77\right)$. In this $\mathrm{pH}$ range, the concentration of the species $\mathrm{Hg}(\mathrm{OH})_{2}$ increases and predominates over all other species, including $\mathrm{HgOH}^{+}$and $\mathrm{HgClOH}$. An increase in $\mathrm{pH}$ produces a decrease in the positive surface charge, and the soil surface becomes less repulsive to cationic species, thus increasing adsorption. At $\mathrm{pH}>6$, adsorption of the $\mathrm{Hg}$ (II) species decreases, as $\mathrm{Hg}(\mathrm{OH})_{2}$ is the predominant metal species (Figure 2). In conclusion, at high $\mathrm{pH}$, the dissolution of soil organic matter and its complexation with $\mathrm{Hg}$ (II) in the bulk solution seems to be the principal factor causing the decrease of $\mathrm{Hg}$ (II) adsorption by soils ${ }^{12}$.

At this point it is interesting to mention that the natural $\mathrm{Hg}$ content in these soils were 281 and $107 \mu \mathrm{g} \mathrm{kg}^{-1}$ for Iara and Carvoeiro 2 , respectively, which can be considered as high, when compared to pristine soils collected elsewhere.

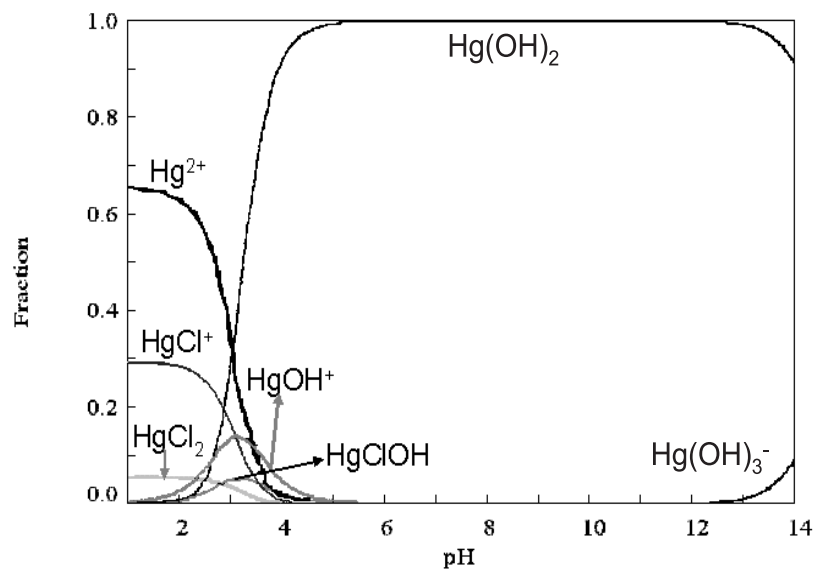

Figure 2. Mercury speciation as a function of $\mathrm{pH}\left(\mathrm{Hg}_{\mathrm{T}}=50 \mathrm{nmol} \mathrm{L^{-1 }}\right.$; $\mathrm{Cl}=$ $\left.0.1 \mu \mathrm{mol} \mathrm{L} L^{-1}\right)$

\section{Influence of dissolved organic matter}

Natural organic matter, such as humic and fulvic acids contain large numbers of functional groups such as carboxylic, phenolic, and alcoholic moieties that interact with soil surface groups and with ions in solution. The binding of mercury in humic-rich environments has already been the subject of many studies ${ }^{25}$. Laboratory experiments performed with iron rich soils containing organic matter indicated that the presence of humic acids increased mercury adsorption ${ }^{12,25,26}$. Recent investigations suggest that $\mathrm{Hg}$ (II) strong binding capability towards humic acid is most probably due to sulfhydryl and thiophenolic groups ${ }^{27}$. Therefore, the presence of natural humic substances in soils reduces the availability (thus the toxicity) of mercury leached from soils to the aquatic systems. One should also take into account that both complexation and reduction of $\mathrm{Hg}$ (II) to volatile $\mathrm{Hg}^{\circ}$ by humic substances can occur simultaneously in tropical soils ${ }^{13}$, as already discussed earlier.

Results showing the influence of dissolved organic matter on mercury adsorption on both soils are shown in Figure 3. It can be observed that there is an inhibitory effect of DOC on the amount of $\mathrm{Hg}$ (II) adsorbed by both types of Amazon soils. Hg removal by soil diminished $76.8 \%$ when DOC was $64.3 \mathrm{mg} \mathrm{C} \mathrm{L}^{-1}$ and $\mathrm{Hg}$ (II) was $66.7 \mu \mathrm{g} \mathrm{L}^{-1}$ for Carvoeiro 2 soil and $83.1 \%$ when DOC was $64.3 \mathrm{mg} \mathrm{C} \mathrm{L}^{-1}$ and $\mathrm{Hg}$ (II) was $50.0 \mu \mathrm{g} \mathrm{L}^{-1}$ for Iara soil compared to the results obtained in the absence of dissolved organic matter.

The efficiency of dissolved organic matter in decreasing $\mathrm{Hg}$ adsorption also depends on the amount of $\mathrm{Hg}$ present in solution. Figure $3 \mathrm{a}$ shows that $\mathrm{Hg}$ (II) removal by Iara soil was $83 \%$ when $50 \mu \mathrm{g} \mathrm{Hg}$ (II) $\mathrm{L}^{-1}$ and $64.3 \mathrm{mg} \mathrm{C} \mathrm{L}^{-1}$ was added, but that $\mathrm{Hg}$ (II) removal by soil was $94 \%$ when $25 \mu \mathrm{g} \mathrm{Hg}$ (II) $\mathrm{L}^{-1}$ and $64.3 \mathrm{mg} \mathrm{C} \mathrm{L}^{-1}$ were used. As the source of DOC used in these experiments was not chemically characterised, further details on the microscopic nature of the interactions $\mathrm{Hg}-\mathrm{DOC}$ remains unknown.
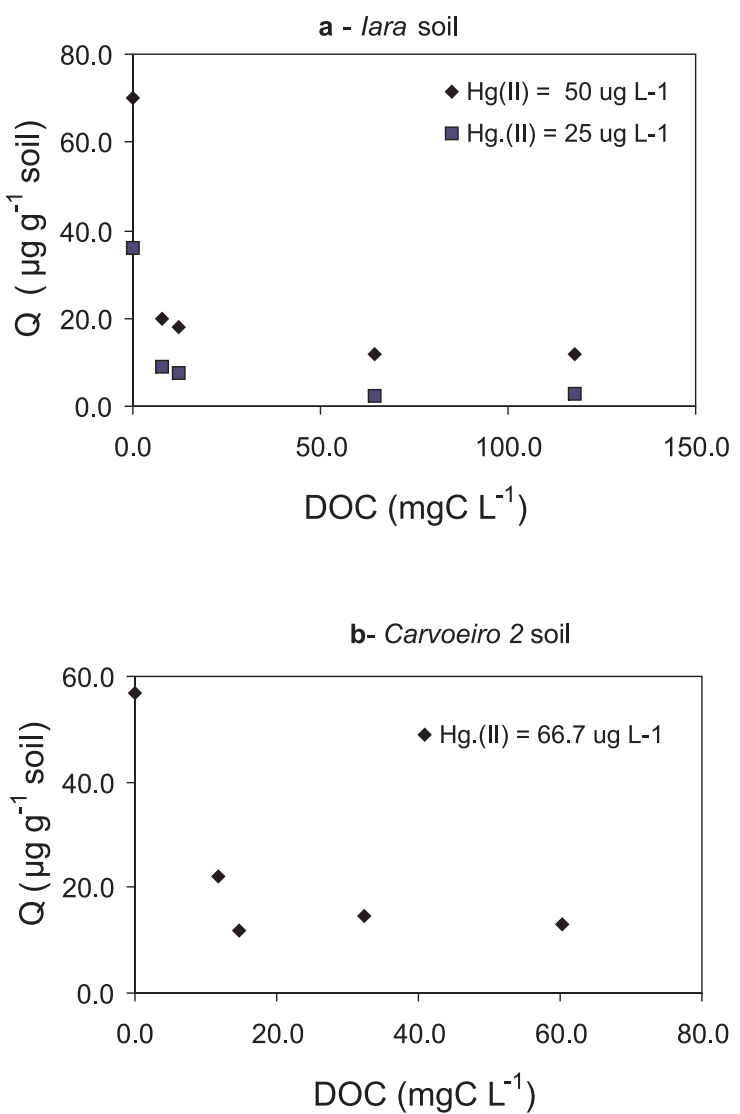

Figure 3. Influence of DOC on the amount of $\mathrm{Hg}$ (II) adsorbed by (a) Iara soil; (b) Carvoeiro 2 soil

\section{Influence of chloride}

The influence of $\mathrm{Cl}^{-}$on the $\mathrm{Hg}$ (II) adsorption in the two types of soil was investigated at a fixed $\mathrm{pH}$ of 5.0. The formation of mercury chloride complexes ${ }^{28}$ promotes a much lower interaction of $\mathrm{Hg}$ (II) at the soil-solution interface.

At neutral or higher $\mathrm{pH}$ values, only very small amount of $\mathrm{Hg}$ chloride complexes can be formed, and the extent of the adsorption depends of the interaction of other forms of $\mathrm{Hg}$ with the soil surface and the complexation of $\mathrm{Hg}$ by the dissolved organic matter. The 
$\mathrm{Hg}$ (II) adsorption by soils is not affected by an increase in chloride concentration when $\mathrm{pH}>7^{19}$. A plot of $\mathrm{Hg}$ species as a function of $\mathrm{pH}$ when $\left[\mathrm{Cl}^{-}\right]=100 \mathrm{mg} \mathrm{L}^{-1}$ can be observed in Figure 4, and helps to explain the above mentioned behavior.

As is shown in Figure 5, increasing the chloride content of the solution resulted in a lower adsorption of $\mathrm{Hg}$ (II) at $\mathrm{pH}$ 5.0. The addition of $\mathrm{Cl}^{-}$anions promotes the formation of very stable $\left(\mathrm{HgCl}_{2}\right)$ and negative charged complexes, especially $\mathrm{HgCl}_{3}^{-}$and $\mathrm{HgCl}_{4}{ }^{2-}$ (Figure 4). Experimental results showed that the effect of chloride on $\mathrm{Hg}$ (II) adsorption also depends on the organic matter content of the soil. For Iara soil (24.7\% organic matter), the $\mathrm{Hg}$ (II) removal decreases $20.0 \%$ when $\left[\mathrm{Cl}^{-}\right]=1000 \mathrm{mg} \mathrm{L}^{-1}$ whereas for Carvoeiro 2 soil ( $10.1 \%$ of organic matter), $\mathrm{Hg}$ (II) removal drops $38.0 \%$ in the same conditions. Similar results were also found by Yin et al. ${ }^{12}$.

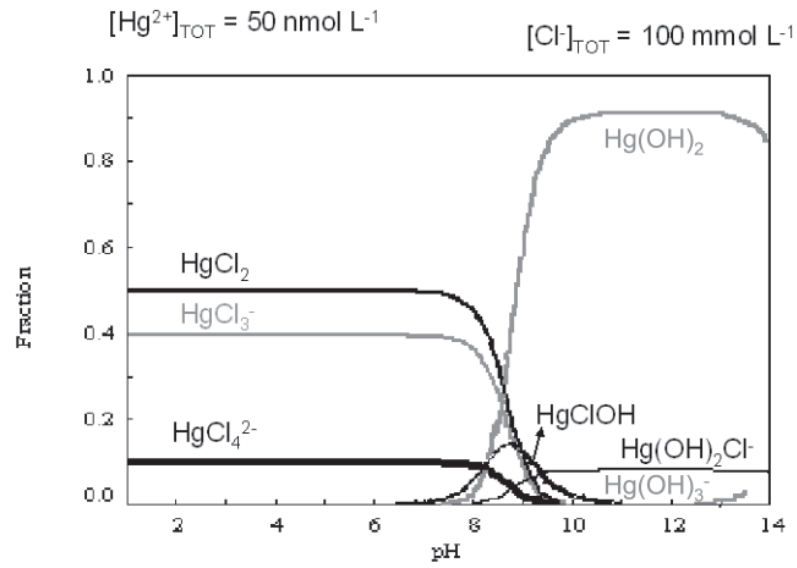

Figure 4. Mercury speciation as a function of $\mathrm{pH}\left(\mathrm{Hg}_{T}=50 \mathrm{nmol} \mathrm{L}^{-1} ; \mathrm{Cl}=\right.$ $100 \mathrm{mmol} \mathrm{L}^{-1}$ )

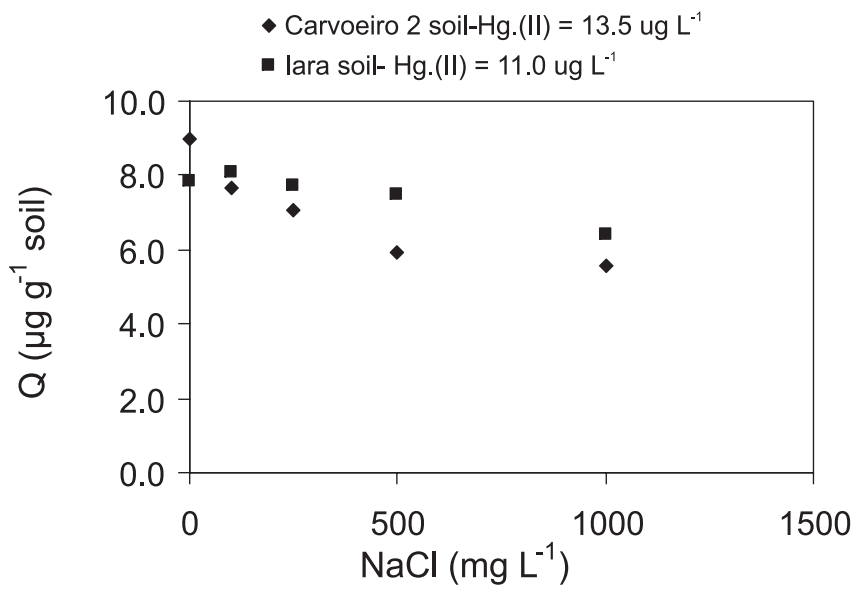

Figure 5. Influence of the ionic strength on the amount of $\mathrm{Hg}$ (II) adsorbed by Iara and Carvoeiro 2 soils

\section{Influence of the initial $\mathrm{Hg}$ (II) concentration}

The effect of the initial $\mathrm{Hg}$ (II) concentration on the adsorption of $\mathrm{Hg}$ was investigated for Carvoeiro2 soil (Figure 6). As shown, an increase in the initial $\mathrm{Hg}$ (II) concentration increased the amount of $\mathrm{Hg}$ (II) adsorbed by the soil and decreased the time needed to reach equilibrium.

\section{Equilibrium isotherms}

Equilibrium isotherms are tools used to evaluate a solid sorption capacity for any given adsorbate present in the aqueous phase. The

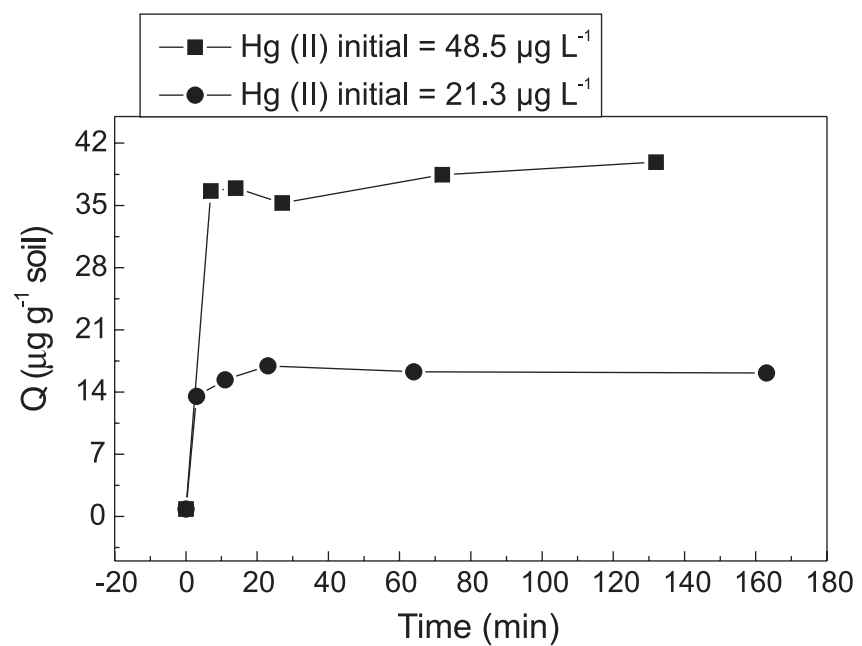

Figure 6. Influence of the initial $\mathrm{Hg}$ (II) concentration on the amount of $\mathrm{Hg}$ (II) adsorbed by Carvoeiro 2 soil

most common models used in this type of experiments are the Langmuir and Freundlich isotherms, although other isotherms have been used ${ }^{29}$. However, it must be taken in account that these models do not reflect microscopic mechanisms of metal uptake at the solidliquid interface, but have to be looked upon as mere mathematical models capable of describing the experimental data. Examination of the experimental data (Table 2, Figure 7a and 7b) suggest that the linear Freundlich isotherm is a good model able to mimic and reproduce $\mathrm{Hg}$ adsorption in soils, and that Iara soil showed a higher capacity for $\mathrm{Hg}$ binding $\left(>\mathrm{K}_{\mathrm{F}}\right)$, as expected because of its higher soil organic matter content, compared to the Carvoeiro 2 sample.

Table 2. Fitting parameters for the Freundlich equation

\begin{tabular}{lcccccc}
\hline Soil & $\mathrm{K}_{\mathrm{F}} / \mathrm{L} \mathrm{g}^{-1}$ & $1 / \mathrm{n}$ & $\mathrm{r}^{2}$ & $\mathrm{SD}^{(1)}$ & $\mathrm{N}^{(2)}$ & $\mathrm{p}^{(3)}$ \\
\hline Iara & 201.14 & 1.72 & 0.955 & 0.089 & 5 & 0.004 \\
Carvoeiro 2 & 35.89 & 1.15 & 0.941 & 0.128 & 6 & 0.001
\end{tabular}

${ }^{(1)}$ Standard Deviation; ${ }^{(2)}$ number of points in the raw data curve; ${ }^{(3)}$ value for the t-test of the slope $=0$

\section{Adsorption kinetics}

Kinetics of $\mathrm{Hg}$ (II) adsorption on both types of soil for an initial $\mathrm{Hg}$ (II) concentration of $50 \mu \mathrm{g} \mathrm{L}^{-1}$ is shown in Figure 8. In the first 10 min, Q increases very fast, where 67 and $37 \mu \mathrm{g} \mathrm{Hg}$ (II) $\mathrm{g}^{-1}$ soil were adsorbed by Iara and Carvoeiro 2 soils, respectively; after this interval of time, adsorption is virtually constant, and $\mathrm{Q}$ reaches a plateau around these values.

Mechanisms of retention and release of soil contaminants are in most cases not instantaneous equilibria but rather time-dependant processes $^{30}$. Therefore, in order to predict the transport and fate of $\mathrm{Hg}$ (II) in soils it is necessary to study the $\mathrm{Hg}$ (II) adsorption rate by soils. When the adsorption follows first order kinetics, it can be modelled using the Lagergren model ${ }^{31}$, expressed as:

$\log _{10}\left(Q_{\mathrm{e}}-\mathrm{Q}\right)=\log _{10} \mathrm{Q}_{\mathrm{e}}-\mathrm{K}_{\mathrm{ad}} \mathrm{t} / 2.303$

where $Q_{e}$ is the amount of metal ion adsorbed at equilibrium by the soil $\left(\mu \mathrm{g} \mathrm{g}^{-1}\right), \mathrm{Q}$ is the amount of metal ion adsorbent at any time $\mathrm{t}$ by the soil $\left(\mu \mathrm{g} \mathrm{g}^{-1}\right)$ and $\mathrm{K}_{\mathrm{ad}}$ is the adsorption rate constant $\left(\mathrm{min}^{-1}\right)$. For the experimental data, plotting $\log _{10}\left(\mathrm{Q}_{\mathrm{e}}-\mathrm{Q}\right)$ against $\log _{10} \mathrm{Q}_{\mathrm{e}}$ did not yield a straight line, as predicted by the Lagergren model, 

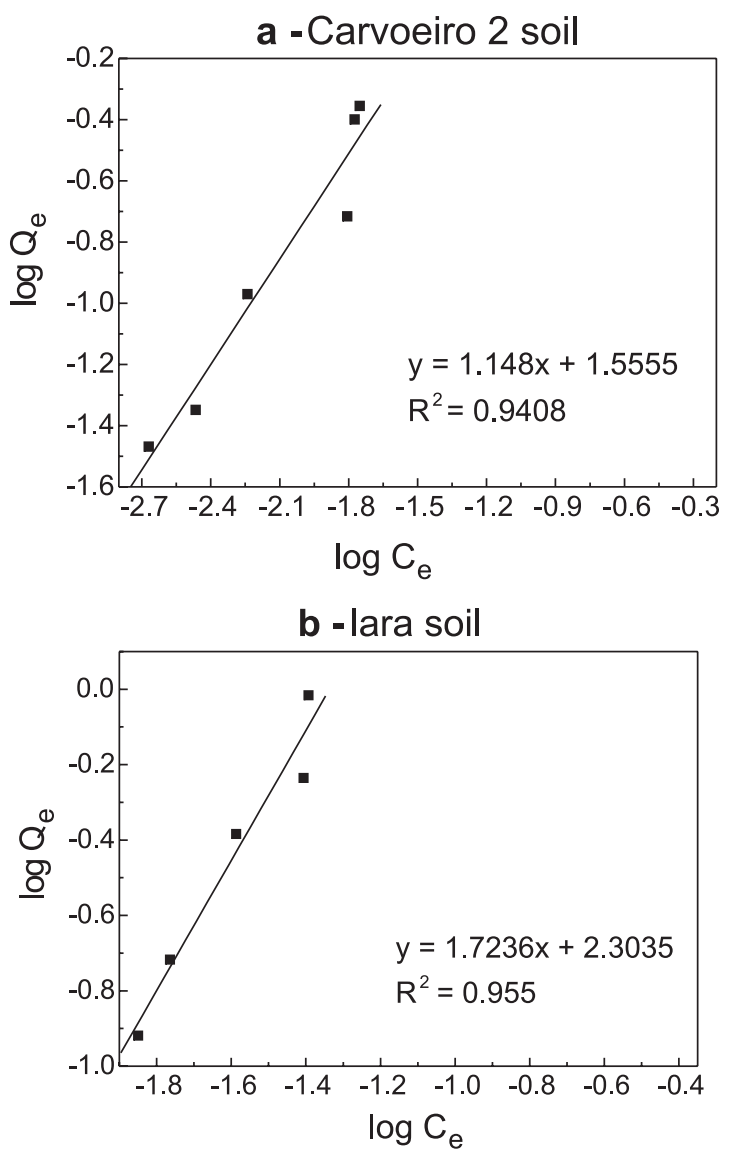

Figure 7. Freundlich isotherms (a) Carvoeiro 2 soil; (b) Iara soil

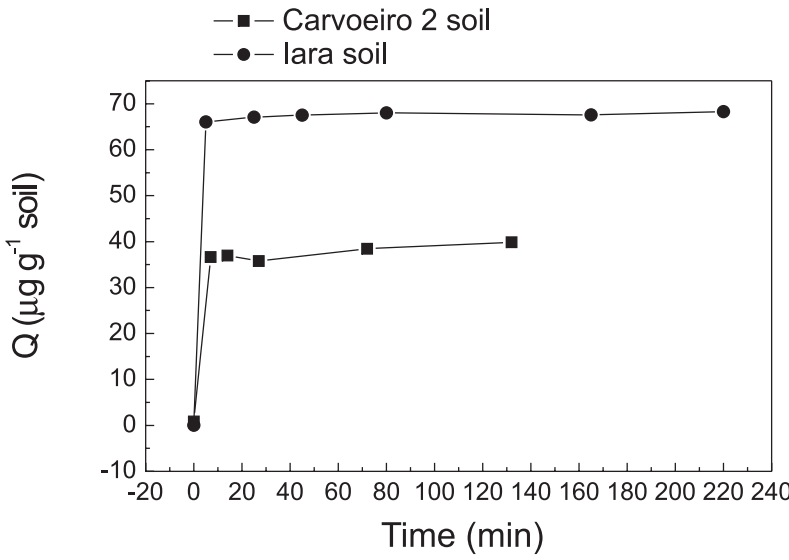

Figure 8. Kinetics of $\mathrm{Hg}$ (II) adsorption obtained for Iara and Carvoeiro 2 soils when the initial $\mathrm{Hg}(\mathrm{II})=50 \mu \mathrm{g} \mathrm{L}^{-1}$ : in both cases

suggesting that the adsorption rate does not depend only on the $\mathrm{Hg}$ (II) concentration. The existence of other related parameters, such as diffusion through soil intraparticle micropores, could be responsible for the poor model fitting.

Yin et al. ${ }^{12}$ proposed that the rate of $\mathrm{Hg}$ (II) adsorption by soils followed a pseudo-second order kinetics, and Vazquez et al. ${ }^{32}$ proposed that the rate of $\mathrm{Hg}$ (II) adsorption by pinus pinaster bark might be considered a pseudo second order reaction. In the pseudo second order model the rate of occupation of adsorption sites is proportional to the square of the number of unoccupied sites

$\mathrm{d} \theta / \mathrm{dt}=\mathrm{k}(1-\theta)^{2}$ and the number of occupied sites is proportional to the fraction of the metal ion adsorbed

$\theta=\mathrm{k}^{\prime} \mathrm{X}_{\mathrm{Hg}}$

where $\theta$ is the coverage ratio with respect to the maximum number of sites $\left(\mathrm{X}_{\mathrm{Hg} \max }\right)$, and $\mathrm{X}_{\mathrm{Hg}}$ is the fraction of $\mathrm{Hg}$ adsorbed $(\mu \mathrm{g} \mathrm{Hg}$ adsorbed / $\mu \mathrm{g} \mathrm{Hg}$ initial). When all sites are occupied, Equation (4) results

$\mathrm{k}^{\prime}=1 / \mathrm{X}_{\mathrm{Hg} \max }$

Differentiating Equation (4) and combination with Equation (2) results in:

$\mathrm{dX}_{\mathrm{Hg}} / \mathrm{dt}=\left(\mathrm{k} / \mathrm{k}^{\prime}\right)\left(1-\mathrm{k}^{\prime} \mathrm{X}_{\mathrm{Hg}}\right)^{2}$

Integration of Equation (5) and combination with Equation (4) gives:

$\mathrm{X}_{\mathrm{Hg}}=\mathrm{kX}_{\mathrm{Hg} \max } \mathrm{t} /(1+\mathrm{kt})$
or $\quad \mathrm{t} / \mathrm{X}_{\mathrm{Hg}}=1 / \mathrm{k} \mathrm{X}_{\mathrm{Hg} \max }+\mathrm{t} / \mathrm{X}_{\mathrm{Hg} \max }$

A plot of $t / X_{\mathrm{Hg}}$ versus $\mathrm{t}$ gives a straight line in the slopes of $1 / \mathrm{X}_{\mathrm{Hg} \max }$ and intercepts of $1 / \mathrm{k} \mathrm{X}_{\mathrm{Hg} \max }$. The fitting parameters for $\mathrm{Hg}$ (II) adsorption by the Iara and Carvoeiro 2 soils are shown in Table 3. The high correlation coefficients values obtained yield estimative values of $\mathrm{X}_{\mathrm{Hg} \max }$ and the rate constant $\mathrm{k}$. One would expected that the adsorption rate to be proportional to the initial mercury concentration, however, results present in Table 3 for Iara and Carvoeiro 2 soils show no proportionality. The pseudo second order model is based on the assumption that the rate limiting step is chemisorption involving valency forces caused by sharing or exchange of electrons between sorbent and sorbate. The existence of other processes such as intraparticle diffusion, mass transfer or ion interaction could be responsible for the lack of proportionality.

Table 3. Fitting parameters for pseudo second order rate

\begin{tabular}{lcccccc}
\hline Soil & $\begin{array}{c}\mathrm{C}_{\circ \mathrm{Hg}(I)} / \\
\mu \mathrm{g} \mathrm{L}^{-1}\end{array}$ & $\mathrm{X}_{\max }$ & $\begin{array}{c}\mathrm{K} / \\
\mathrm{min}^{-1}\end{array}$ & $\mathrm{r}^{2}$ & $\mathrm{SD}$ & $\mathrm{p}$ \\
\hline Iara & 35 & 0.971 & 0.594 & 0.996 & 2.851 & 0.0040 \\
Iara & 108 & 0.969 & 0.177 & 0.999 & 5.460 & $<0.0001$ \\
Iara & 162 & 0.930 & 1.579 & 1.000 & 0.441 & $<0.0001$ \\
Carvoeiro 2 & 21 & 0.899 & 1.070 & 1.000 & 0.073 & $<0.0001$ \\
Carvoeiro 2 & 49 & 0.845 & 1.033 & 1.000 & 0.542 & $<0.0001$ \\
\hline
\end{tabular}

Although experimental data yield a good fit this simplified model, one must bear in mind that the model assumes that all adsorption sites are homogeneous, and does not consider the heterogeneous nature of soils.

\section{CONCLUSIONS}

$\mathrm{Hg}$ (II) sorption by Amazonian soils depends strongly on the $\mathrm{pH}$. In the $\mathrm{pH}$ range 3.0-5.0 maximum adsorption occurred with both soils $(>90 \%)$. There is an inhibitory effect of DOC on the extent of $\mathrm{Hg}$ (II) adsorption by the soils. The efficiency of the dissolved organic matter in decreasing $\mathrm{Hg}$ (II) adsorption also depends on the amount of $\mathrm{Hg}$ (II) added, being higher at lower $\mathrm{Hg}$ concentrations.

Increasing the chloride content in the aqueous solution results in a lower adsorption of $\mathrm{Hg}$ (II) at $\mathrm{pH} 5.0$, which can be partially 
explained by assuming that chloride acts as a strong complexing agent for mercuric ions, thus promoting the formation of very stable and negatively charged complexes, especially $\mathrm{HgCl}_{2}$ and $\mathrm{HgCl}_{3}$. The effect of chloride on $\mathrm{Hg}$ (II) adsorption also depends on the organic matter content of the soil, where soils with higher organic matter content are less affected by this complexing agent.

The linear Freundlich isotherm yielded a good model for the $\mathrm{Hg}$ (II) adsorption in the two types of soils studied. Iara soil showed a higher capacity for $\mathrm{Hg}$ binding (larger $\mathrm{K}_{\mathrm{F}}$ ) than Carvoeiro 2 soil, in accordance to their organic matter contents.

The kinetics of $\mathrm{Hg}$ (II) adsorption on Iara and Carvoeiro 2 soils was very fast, as adsorption was nearly complete in the first 10 minutes of batch experiments. The $\mathrm{Hg}$ (II) adsorption by these two Amazonian soils followed a pseudo-second order kinetics.

Considering that the two samples were collected at the first 10 $\mathrm{cm}$ (A horizon), one can expect that any atmospheric mercury inputs to this region, estimated to be around $22 \mathrm{ug} \mathrm{m}^{2} \mathrm{y}^{-1}$ or approximately 15 t per year over the entire basin $\left(\sim 690,000 \mathrm{~km}^{2}\right)$, are very likely to remain tightly bound to the soil ${ }^{8}$. This behaviour makes the soil to act as the major sink of mercury in this basin, due to the combination of the very fast adsorption kinetics observed with these types of soil, despite the low $\mathrm{pH}$ and high content of dissolved organic carbon in the vast majority of waters from the Negro River basin.

Many investigations in Amazon tropical areas ${ }^{6,8,33,34}$ have demonstrated that soils act as a natural filter of mercury deposited from total precipitation due to adsorption and accumulation associated to iron and aluminum oxy-hydroxos. Silva ${ }^{35}$ demonstrated that soils from Negro River Basin accumulated around $13 \mathrm{t}$ of mercury per year, where waters exported $2 \mathrm{t}$ of mercury per year. This represents a retention capacity of around $87 \%$ of the total mercury deposited in the region, what is due to soil properties.

Recent studies ${ }^{36-38}$ have shown that deforestation decreases the soil retention capacity of mercury. Magarelli and Fostier ${ }^{36}$ have recently showed that, despite the strong adsorption into soils, mercury fluxes at the soil/atmosphere interface increases up to 20 times in deforested areas compared to soils with native vegetation. This behaviour reinforces the need for better understanding the mercury cycle in this region in terms to implement effective environmental management options for the Amazon. So, under the environmental point of view, following the trend recently observed in deforestation in the Amazon one would expect an increase in mercury concentration in the water bodies over to region.

\section{ACKNOWLEDGMENT}

The authors would like to thank Prof. C. H. Collins for revising the manuscript. This work was supported by FAPESP (grant 00/ 13517-1).

\section{REFERENCES}

1. Niel, D.H.; Appl. Microbiol. Biotechnol. 1999, 51, 730.
2. Wagner-Döbler, I.; Appl. Microbiol. Biotechnol. 2003, 62, 124.

3. Bisinoti, M. C.; Jardim, W. F.; Quim. Nova 2004, 27, 593.

4. Lacerda, L.; Salomons, W.; Série Tecnologia Ambiental, CETEM: Rio de Janeiro, 1992.

5. Roulet, M.; Lucotte, M.; Saint-Aubin, A.; Tran, S.; Rhéaut, I.; Farella, N.; Da Silva, E. D.; Dezencourt, J.; Passos, C. J. S.; Soares, G. S.; Guimarães, J. R. D.; Mergler, D.; Amorim M.; Sci. Total Environ. 1998, 223, 1.

6. Roulet, M.; Lucotte, M.; Canuel, R.; Rhéaut, I.; Tran, S.; Gog, Y. G. F.; Farella, N.; Vale, R. S.; Passos, C. J. S.; N.; Da Silva, E. D.; Mergler, D.; Amorim M.; Sci. Total Environ. 1998, 213, 203.

7. Roulet, M.; Lucotte, M.; Farella, N.; Serique, G.; Coelho H.; Passos, C. J. S.; Da Silva, E. D.; De Andrade, P. S.; Mergler, D.; Guimarães, J. R. D.; Amorim M.; Water, Air, Soil Pollut. 1999, 112, 297.

8. Fadini, P. S.; Jardim, W. F.; Sci. Total Environ. 2001, 275, 71.

9. Barbosa, A. C.; de Souza, J.; Dorea, J. G.; Jardim, W. F.; Fadini, P. S.; Arch. Environ. Contam. Toxicol. 2003, 45, 235.

10. Schlüter, K.; Gäth, S.; Water, Air, Soil Pollut. 1997, 96, 301.

11. Schlüter, K.; Environ. Geol. 1995, 30, 266.

12. Yin, Y.; Allen, H.; Li, Y.; Huang, C. P.; Sanders, P.; J. Environ. Qual. 1996, $25,837$.

13. Rocha, J.; Sargentini, E.; Zara, L.; Rosa, A.; dos Santos, A.; Burba, P.; Talanta 2000, 53, 551.

14. Schnoor, J.; Environmental modelling. Fate and Transport of Pollutants in Water, Air and Soil, J.Wiley \& Sons. Inc.: New York, 1996.

15. Canela, M.; Jardim, W. F.; J. Braz. Chem. Soc. 1997, 8, 421.

16. Yin, Y.; Allen, H.; Huang, C. P.; Environ. Sci. Technol. 1997, 31, 496.

17. Wang, D.; Qing, C.; Guo, W.; Guo, Y.; Water, Air, Soil Pollut. 1995, 95, 35 .

18. Grigal, D.; J. Environ. Qual. 2003, 32, 393.

19. Melamed, R., Villas Boas, R. C.; Sci. Total Environ. 1998, 213, 151.

20. Oliveira, S.; Melfi, A.; Fostier, A.; Forti, M.; Fávaro, D.; Boulet, R.; Water, Air, Soil Pollut. 2001, 26: 321.

21. Bareli, N.; Caracterização granulométrica, mineralógica e microestrutural de solos usados como base de pavimentação rodoviária - Relatório Semestral, Instituto de Química, Universidade Estadual Paulista, Araraquara, 1979, p. 38.

22. Pasquini, C.; Jardim, W.F.; Faria, L. C.; J. Automat. Chem. 1988, 10, 188

23. Barrow, N. J.; Cox, V. C.; J. Soil Sci. 1992, 43, 305.

24. Brady, N.; Weil, R.; The nature and properties of soil, 12 ed.; Upper Saddle River: New York, 1999.

25. Xu, H.; Allard, B.; Water, Air, Soil Pollut. 1991, 56, 709.

26. Lumsdon, D.; Evans, L.; Bolton, K.; J. Soil Contam. 1995, 4, 137.

27. Xia, K.; Skylberg, U.; Bleam, W.; Bloom R.; Nater, E.; Helmke, P.; Environ. Sci. Technol. 1999, 33, 257.

28. Evans, L. J.; Environ. Sci. Technol. 1989, 23, 1046.

29. Ho, Y.; Porter, J.; Mckay, G.; Water, Air, Soil Pollut. 2002, 141, 1.

30. Sparks, D.; Kinetics of soil chemical processes, New York: USA, 1989.

31. Lagergren, S.; Kungliga Svenska Vetenskapsakademiens. Handlinglar, Band 1898, 24, 1 .

32. Vázquez, G.; Alvarez, S. G.; Freire, M.; López-Lorenzo, M.; Antorrena, G.; Bioresour. Technol. 2002, 82, 247.

33. Hylander, L. D.; Meili, M.; Oliveira, L. J.; Silva, E. C.; Guimarães, J. R. D.; Araújo, D. M.; Neves, R. P.; Stachiw, R.; Barros, A. J. P.; Silva, G. D.; Sci. Total Environ. 2000, $260,97$.

34. Dematté, J. L. I.; Manejos de solos ácidos dos trópicos úmidos, região Amazônica, Fundação Cargil: Campinas-Brasil, 1988.

35. Silva, G. S.; Tese de Doutorado, Universidade Estadual de Campinas, Brasil, 2004.

36. Magarelli, G.; Fostier, A. H.; Quim. Nova, in press.

37. Zhang, H.; Lindberg, S. E.; Marsik, F.J.; Keeler, G. J.; Water, Air, Soil Pollut. 2001, 126, 151.

38. Carpi, A.; Lindberg, S. E.; Atmos. Environ. 1998, 32, 873. 